\title{
Isolation and purification of a squamous cell carcinoma of the head and neck-associated antigen identified by autologous antibody
}

\author{
Daniel R. Vlock a , Avishag Toporowicz a , Beth Arnold ${ }^{\text {a }}$, Donald Aul b, \\ J. Philip McCoy, Jr. ${ }^{c}$, Thomas E. Carey ${ }^{\mathrm{d}}$ and William E. Brown ${ }^{\mathrm{b}}$ \\ a Department of Medicine, Pittsburgh Cancer Institute, University of Pittsburgh School of Medicine, Pittsburgh, PA (USA) \\ ${ }^{b}$ Department of Biological Sciences, Carnegie Mellon University, Pittsburgh, PA (USA), ' Department of Pediatrics, Cooper Hospital, \\ Robert Wood Johnson Medical School, Camden, NJ (USA) and ' Department of Otolaryngology, University of Michigan, Ann Arbor, \\ MI (USA)
}

(Received 25 September 1992)

Key words: Neoplasm; Tumor-associated antigen; Antibody; Autologous antibody; Immunology; Serology; (Head); (Neck)

\begin{abstract}
We have previously shown that detection of autologous antibody activity to squamous cell carcinoma of the head and neck may be augmented by dissociation of immune complexes. Western blot analysis with autologous antibody has identified a $60 \mathrm{kDa}$ squamous cell carcinoma of the head and neck-associated antigen in spent media and immune complex-dissociated serum ultrafiltrate not recognized by normal human sera. Antigen-containing fractions of spent media were eluted from anion exchange columns immediately after serum albumin indicating that the antigen has an acidic $\mathrm{p} I<4$. Preparative purification of the squamous cell carcinoma antigen was accomplished by anion exchange of concentrated spent media (protein concentration 300 $\mathrm{mg} / \mathrm{ml}$ ) followed by lectin affinity chromatography with a Triticum vulgaris column. A single $60 \mathrm{kDa}$ band was detected by silver stain and Western blot in antigen-containing fractions eluted following lectin affinity chromatography and SDS-PAGE. Final concentration of the antigen was determined to be $1 \mu \mathrm{g} / \mathrm{ml}$ of protein with relative activity increased $1600 \times$ over unfractionated spent media. We conclude that a squamous cell carcinoma of the head and neck-associated antigen, detected by autologous antibody, is an acidic $60 \mathrm{kDa}$ glycoprotein.
\end{abstract}

\section{Introduction}

One of the major focuses of tumor immunology has been the detection and characterization of tumor-associated antigens. By identifying antigens that are restricted to tumor cells it may be possible to better understand the nature of the host-tumor interaction and tailor more effective agents for immunodiagnostic and therapeutic use. A variety of antibodies have been utilized to detect tumor-associated antigens. These antibodies have included polyclonal xenogeneic and allogeneic antisera and more recently, monoclonal murine

Correspondence to: D.R. Vlock, Hematology/Oncology Division, Brigham and Women's Hospital, Harvard Medical School, 75 Francis Street, Boston, MA 02115, USA.

Abbreviations: SCCHN, squamous cell carcinoma of the head and neck; FCS, fetal calf serum; PA, protein A hemadsorption; AD\&U, acid dissociation and ultrafiltration; SDS-PAGE, sodium dodecyl sulfate-polyacrylamide gel electrophoresis; PBS, phosphate-buffered saline; TBS, Tris-buffered saline; GlcNAc, $N$-acetylglucosamine. and human antibodies [1-3]. Unfortunately, these antibodies have generally been found to detect normal cellular products rather than tumor-restricted antigens when sufficiently studied.

Studies defining tumor-associated antigens in squamous cell carcinoma of the head and neck (SCCHN) have yielded similar results. While the development of monoclonal antibodies directed against SCCHN have been reported [4-8], they have been found to react with normal cell constituents. To avoid the difficulties associated with the use of heteroantisera, we have focused our attention on the autologous immune response. The advantage of studying autologous antibody reactivity is that it may detect antigens not apparent to heteroantisera. Because these antigens are produced by the host they may detect biologically relevant antigens that could shed light on the host-tumor interaction.

Previous studies have noted autologous antibody reactivity against SCCHN in 24 of 41 systems tested with a median titer of $1: 4[9,10]$. In the majority of cases, autologous antibody reactivity could only be 
detected in undiluted serum precluding further analysis. The low incidence and weak titer of autologous antibody to cancer has raised questions regarding the relevance of humoral immunity. The presence of circulating antigen in patients and the resulting formation of immune complexes may explain this. We have demonstrated that dissociation of immune complexes by acidification and ultrafiltration of sera augments autologous antibody reactivity in the majority of cases studied $[9,11]$. These findings support the hypothesis that autologous antibody to SCCHN and melanoma may be obscured by circulating antigen and that immune complexes may provide a readily accessible source of relevant antigen and antibody. In melanoma, we have noted correlations between the presence and titer of host-derived antibody reactivity and clinical course and prognosis $[12,13]$. Serial studies have been performed on 6 patients with SCCHN and correlations with clinical course have been noted as well [14]. Our work and that of others [15] would support the conclusion that circulating immune complexes may be a reservoir for tumor-associated antigens and antibody relevant to the host.

What remains to be determined is the nature and biological significance of the antigens recognized by the host. In melanoma we have succeeded in purifying, to apparent homogeneity, a shed $66 \mathrm{kDa}$ tumor-associated antigen identified by autologous antibody $[13,16]$. This antigen has been noted to be an unusually acidic glycoprotein $(\mathrm{p} / 2-3)$ that is sensitive to digestion with trypsin and neuraminidase. We have begun to extrapolate these findings to explore the nature of antigens recognized by patients with SCCHN. We now report what is to our knowledge the first successful isolation and purification, to apparent homogeneity, of a SCCHN-associated antigen identified by autologous antibody.

\section{Materials and Methods}

Cell culture and source of antigen. The acquisition, establishment and maintenance of SCCHN and other cell lines have been reported previously $[9,11]$. SCCHN cell lines were maintained in culture with minimal essential medium (MEM) plus 1\% nonessential amino acids, $2 \mathrm{mM}$ L-glutamine, $15 \%$ fetal bovine serum, 100 $\mathrm{IU} / \mathrm{ml}$ penicillin and $100 \mu \mathrm{g} / \mathrm{ml}$ streptomycin. Squamous cell carcinoma lines UM-SCC-17A was derived from the primary tumor specimen of a patient with a T1N0M0 SCC of the left true vocal cord, treated and followed in the Department of Otolaryngology at the University of Michigan [17]. The source of antigen was pooled spent tissue culture media from UM-SCC 17A, which had been concentrated (protein concentration $300 \mathrm{mg} / \mathrm{ml}$ ) and stored at $-70^{\circ} \mathrm{C}$. Antigen was also obtained from autologous serum ultrafiltrate obtained following acid dissociation and ultrafiltration (see below). Serum ultrafiltrate was concentrated to the initial serum volume, dialyzed against PBS to correct $\mathrm{pH}$ and stored at $-70^{\circ} \mathrm{C}$.

Protein $A$ hemadsorption ( $P A)$. Indicator cells for protein A mixed hemadsorption tests were prepared by conjugating staphylococcal protein A (Pharmacia Fine Chemicals) to the surface of selected human blood group O-Rh positive red blood cells with $0.01 \% \mathrm{CrCl}_{3}$ at $\mathrm{pH} 5.0$ [18]. Target monolayers were seeded in micro-Terasaki assay plates and reacted with serial dilutions of autologous native serum, or derived fractions. After incubation of target cells with sera at $37^{\circ} \mathrm{C}$, wells were washed 3 times with PBS containing 2\% immunoglobulin-free fetal calf serum (FCS) at $37^{\circ} \mathrm{C}$ and $0.01 \mathrm{ml}$ of an $0.15 \%$ suspension of indicator cells were added to each well. Plates were washed 2-4 times with PBS-2\% immunoglobulin-free FCS after $45 \mathrm{~min}$, and positive cells read as follows: $(+)$ cells were those which bear a $>50 \%$ erythrocyte rosette. The endpoint of the assay is read as the last well with $10 \%$ of target cells $(+)$.

Acid dissociation and ultrafiltration $(A D \& U)$ of serum. The method initially described by Sjogren et al. [19] was used to dissociate immune complexes in serum to augment autologous antibody reactivity. The analysis reported in this study was performed using a serum sample obtained 7 years after successful surgical excision from the donor of the UM-SCC-17A cell line Briefly, a $60 \mathrm{ml}$ ultrafiltration chamber and Amicon XM-100 membrane (Amicon Corporation) were used. 2-3 $\mathrm{ml}$ of prefiltered $(0.45 \mu \mathrm{m}$, Millipore) serum was

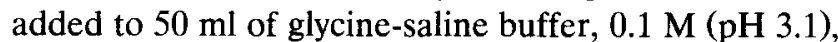
in the ultrafiltration chamber. Ultrafiltration was performed at $4^{\circ} \mathrm{C}$ under $10 \mathrm{lb} /$ inch $^{2} \mathrm{~N}_{2}$ until the original volume of the test solution is reached. This was repeated twice and then the preparation was washed three times with $50 \mathrm{ml}$ PBS, and concentrated to the original volume of the test solution. The total time involved varied from 24 to $48 \mathrm{~h}$ depending on the serum used.

Detection of isolated antigen by competitive inhibition. To determine whether the isolated fraction of spent media contained the antigen of interest, competitive inhibition by the isolated antigen for antibody directed against autologous UM-SCC-17A cells was performed. Fractions tested for the presence of SCCHN-associated antigen were mixed at a $1: 1$ ratio with autologous antibody, incubated for $30 \mathrm{~min}$ at $4^{\circ} \mathrm{C}$ then $30 \mathrm{~min}$ at $37^{\circ} \mathrm{C}$ and retested utilizing PA against UM-SCC-17A cells (see above). A 2-fold drop in autologous antibody titer was considered to be indicative of the presence of antigen in the fraction tested.

$S D S-P A G E$ and transfer to nitrocellulose of SCCHNassociated antigens. One-dimensional SDS-PAGE was performed after the method of Laemmli [20] with 12.5 
$\mathrm{cm}$ gels of $10 \%$ acrylamide. Antigen-containing fractions of spent media were dissolved in $0.025 \mathrm{M}$ Tris- $\mathrm{HCl}$ (pH 6.8), 2\% SDS, 10\% glycerol, 5\% 2-mercaptoethanol with $0.001 \%$ Bromphenol blue dye marker. Final sample volumes contained $20 \mu \mathrm{g}$ protein in 0.1 $\mathrm{ml}$. Electrophoresis was carried out with a current of $20 \mathrm{~mA}$ until the Bromphenol blue marker reached the margin of the gel. The methods of Towbin et al. [21] were used for transfer of proteins with a Hoefer transblot apparatus (Hoeffer Scientific Instruments, San Francisco, CA). Transfer was performed at $63 \mathrm{~V}$ for 1 h. The nitrocellulose $(0.2 \mu \mathrm{m}$, Scheicher \& Schuell, Keene, NH) to which electrophoretic transfer was accomplished was stained immunologically and with biotinylated lectins.

Immune detection of transferred proteins. Following transfer to nitrocellulose, the sheet was quenched for a minimum of $2 \mathrm{~h}$ in Tris-buffered saline (TBS) $(\mathrm{pH} 7.5$ ) containing plus $3 \%$ gelatin on a rocker. The nitrocellulose was overlaid with antibody diluted in TBS plus $0.05 \%$ Tween-20 and $1 \%$ gelatin (TBS-Tween) was incubated on a rocker at $20^{\circ} \mathrm{C}$ for $3 \mathrm{~h}$. The paper was washed with TBS-Tween for $5 \mathrm{~min} \times 5$. Then alkaline phosphatase-conjugated rabbit anti-human Ig antibody (Cappel), diluted with TBS-Tween was incubated with the nitrocellulose paper at room temperature while rocking for $\mathrm{l} \mathrm{h}$. After washing to remove unbound conjugate, the nitrocellulose paper was developed for $15 \mathrm{~min}$ in 5-bromo-4-chloroindolyl phosphate and $\mathrm{Ni}$ troblue tetrazolium. The reaction was stopped by removing the nitrocellulose and placing it in a fresh container of $\mathrm{dH}_{2} \mathrm{O}$ and washing $10 \mathrm{~min} \times 2$.

Lectin binding. Following transfer of the antigen to nitrocellulose, the strips were quenched in TBS plus $10 \%$ BSA and lectin binding was performed. Biotinylated lectin $(25 \mu \mathrm{g} / \mathrm{ml})$ (EY Laboratories, San Mateo, $\mathrm{CA}$, and Sigma Chemical Co., St. Louis, MO) was diluted in TBS and incubated with the nitrocellulose strips for one $h$ at room temperature. The nitrocellulose strips were then washed in TBS and incubated with an avidin-biotin peroxidase complex for $1 \mathrm{~h}$ using reagents from the Vectastain $\mathrm{ABC}$ Kit (Vector Laboratories, Burlingame, CA). Lectin binding was visualized using diaminobenzidine as the chromogen.

Enzymatic digestion. Nitrocellulose-bound, partially purified antigen obtained following anion exchange chromatography (see below) and SDS-PAGE, was incubated with $5 \cdot 10^{-5}$ units of neuraminidase (Vibrio cholera isolate, Calbiochem, San Diego, CA) in $0.5 \mathrm{ml}$ of dilution buffer $(50 \mathrm{mM}$ sodium acetate, $154 \mathrm{mM}$ $\mathrm{NaCl}, 4 \mathrm{mM} \mathrm{CaCl}$ ( $\mathrm{pH} \mathrm{5.5))} \mathrm{containing} 0.5 \mathrm{mg} / \mathrm{ml}$ of lysozyme as a carrier protein, at $37^{\circ} \mathrm{C}$ for $30 \mathrm{~min}$. The reaction was stopped by addition of $250 \mathrm{mM}$ EDTA (pH 7.0). Following exposure to neuraminidase, the treated antigen was tested by immunoblotting. Partially purified antigen, obtained following anion-exchange chromatography, was subjected to digestion with a $1 \%$ solution of pepsin (Millipore Corp.), at pH 3.0. or

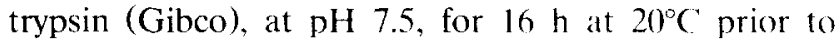
SDS-PAGE and immunoblotting.

\section{Preparative purification}

DEAE-anion-exchange chromatography. $3 \mathrm{ml}$ of concentrated, unfractionated spent media (protein concentration $300 \mathrm{mg} / \mathrm{ml}$ ) was applied to a $1.8 \times 15.5 \mathrm{~cm}$ Whatman DE-52 weak anion-exchange column that had been equilibrated with $0.02 \mathrm{M}$ Tris formate $(\mathrm{pH}$ 8.0). The $\mathrm{pH}$ was changed in step-wise fashion with 0.5 $\mathrm{M}$ sodium formate ( $\mathrm{pH} 2.8$ ). Fractions were collected, dialyzed against PBS and tested for the presence of antigen by competitive inhibition.

Lectin affinity chromatography. Following anion-exchange chromatography, $10 \mathrm{ml}$ of antigen containing fractions (protein concentration $100 \mu \mathrm{g} / \mathrm{ml}$ ) were applied to a $10 \mathrm{ml}$ Triticum vulgaris affinity column (E-Y Laboratories, San Mateo, CA), pre-equilibrated with PBS at $4^{\circ} \mathrm{C}$. The antigen was incubated on the column for $15 \mathrm{~min}$ and the column was washed with 5 vol. of PBS. Antigen bound to the column was eluted with 0.5 $\mathrm{M} \mathrm{N}$-acetylglucosamine (GlcNAc) in $0.15 \mathrm{M} \mathrm{NaCl}$. Fractions were collected, dialyzed and tested for the presence of antigen by competitive inhibition.

Determination of yield and activity. Measurement of protein concentration following each purification step was determined by the Bradford dye-binding procedure [22] or bicinchronic acid assay (micro-BCA assay, Pierce, Rockford, IL) with the exception of final purification step where the level was below the limits of detection and was estimated based on the appearance of a silver-stained SDS-PAGE gel of the antigen [23,24]. Assessment of activity of antigen obtained at each purification step was expressed as the dilution of antigen required to give the same reduction in autologous antibody titer against SCCHN cell line UM-SCC-17 as unfractionated spent media.

\section{Results}

Isolation of an SCCHN antigen identified by autologous antibody

The specificity of the antigen detected by autologous antibody from the donor of the UM-SCC-17A cell line has previously been reported [14]. Briefly, the antigen was noted to be present on $7 / 7 \mathrm{SCCHN}$ and $2 / 2$ melanoma cell lines. Autologous antibody did not react with neuroblastoma, glioma, renal cell, bladder, or colon carcinoma cell lines, fetal fibroblasts, pooled lymphocytes, platelets red blood cells or fetal calf serum. In addition, sera from six normal individuals did not react with SCCHN cell lines both before and after immune-complex dissociation. Co-incubation of 
antibody with spent media from autologous tumor cells or with antigen-containing ultrafiltrate obtained from autologous serum by AD\& $U$ inhibited antibody binding to UM-SCC-17 cells (Table I). Conversely, co-incubation of autologous antibody with fetal calf serum, tissue culture media, or spent media obtained from an unreactive bladder carcinoma cell line (HTB4) did not inhibit antibody binding. This suggests that tumor-associated antigens detected by AD\&U antibody are present in the sera of patients with SCCHN and are also shed or secreted by their tumor cells in culture.

We have focused our current study on antigen recovered in spent media as this represents a continuously accessible source of antigen for study. Western blot analysis (Fig. 1) with immune complex-dissociated autologous sera (lane C) has identified an antigen with a molecular weight of $60 \mathrm{kDa}$ in spent media. This antigen is not recognized by normal human (lane A) or native autologous sera (lane B). A similar $60 \mathrm{kDa}$ band was also detected in autologous serum ultrafiltrate (Fig. 7). As is illustrated in Fig. 2, binding of antibody to this antigen was diminished by absorption of sera with the autologous SCCHN cell line UM-SCC-17A (lane 17A) but not after absorption with fetal fibroblasts (lane FF) when compared to unabsorbed control antibody (lane C).

\section{Anion-exchange chromatography}

Anion-exchange chromatography was employed as the initial step in separating the antigen from other components present in spent media. As illustrated in Fig. 3b, autologous antibody reactivity was reduced by samples obtained from fractions 86-92. This corresponds to the small shoulder of the large peak noted on the chromatograph (see "**, Fig. 3a). No other fractions were noted to contain the antigen. The location of the antigen-containing fractions which eluted

\section{TABLE I}

Competitve inhibition of autologous antibody reactivity against UM$S C C-17$

$A D \& U$, autologous sera obtained following acid dissociation and ultrafiltration (see Materials and Methods); $+\mathrm{M} / 17 \mathrm{~A}$, unfractionated spent media from UM-SCC-17A; + ULF, autologous eluate obtained following ultrafiltration; + FCS, fetal calf serum; +M, unconditioned tissue culture media; + HTB4, spent media from an unrelated bladder carcinoma cell line.

\begin{tabular}{ll}
\hline Sera & Maximum antibody titer \\
\hline Native & 0 \\
AD\&U & $1: 2048$ \\
$\quad+\mathrm{M} / 17 \mathrm{~A}$ & $1: 256$ \\
$\quad+\mathrm{ULF}$ & $1: 16$ \\
$\quad$ - M & $1: 2048$ \\
+ FCS & $1: 2048$ \\
+ M/HTB4 & $1: 2048$ \\
\hline
\end{tabular}

\section{UM-SCC 17A}

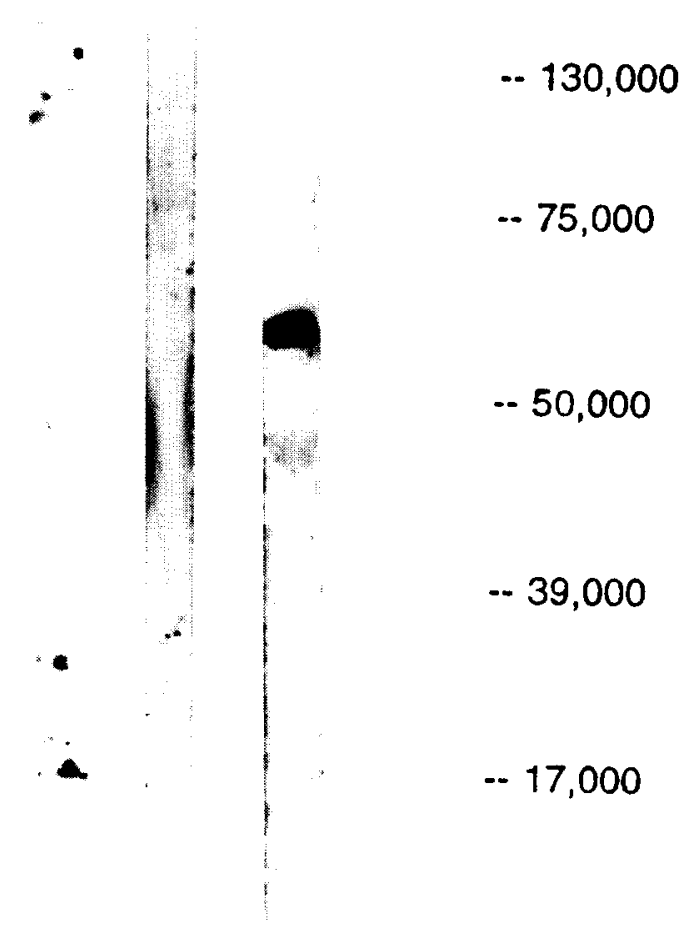

\section{A B C}

Fig. 1. Western blot analysis of spent media from UM-SCC-17A Autologous immune complex dissociated sera detected a $60 \mathrm{kDa}$ antigen in spent media (lane C). The antigen was not detected with normal human sera (lane A) or native autologous sera (lane B).

after bulk serum albumin indicating that this antigen has an acidic $\mathrm{p} I<4$.

\section{Lectin binding}

Following anion-exchange chromatography, binding by a panel of biotinylated lectins to the antigen was evaluated. Binding was evaluated visually and the relative intensity of binding expressed on a four point scale $(0$ to +3$)$. As summarized in Table II, binding by 9 of 13 biotinylated lectins to the antigen was noted.

\section{Lectin affinity chromatography}

Lectin binding was noted to be quite strong with Triticum vulgaris (see above and Table II). Further purification of the antigen was performed with an affinity column of that lectin (see Materials and Methods). Shown in the Fig. 4, activity, detected by competitive inhibition, was recovered in fractions $27-31$, following elution with $0.5 \mathrm{M}$ GlcNAc (see arrow). 


\section{UM-SCC-17A}

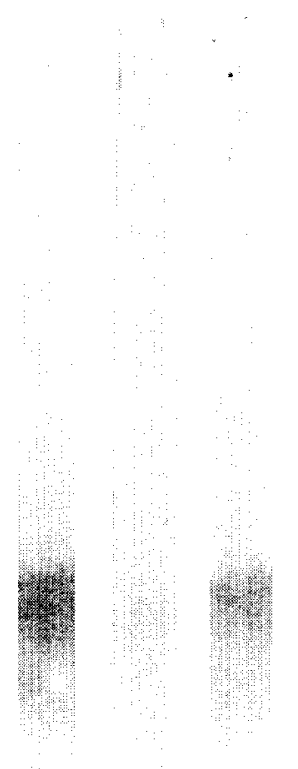

\section{17 FF}

Fig. 2. Western blot analysis of SCCHN antigen. Partially purified antigen obtained following anion exchange chromatography (see Fig. 4) was subjected to Western blot analysis and immunoblot with autologous antibody. As noted previously (Fig. 2), a $60 \mathrm{kDa}$ band is noted (lane $\mathrm{C}$ ). Preincubation of antibody with autologous cell line UM-SCC-17A (lane 17A) diminished binding. No reduction in binding was noted following preincubation with fetal fibroblasts (lane FF). The excessive width of the bands are due to intentional overloading of the gel to better aid in detecting differences.

\section{Enzymatic digestion of SCCHN antigen}

As illustrated in Fig. 5, exposure of partially purified antigen to pepsin and trypsin, for $16 \mathrm{~h}$ at $20^{\circ} \mathrm{C}$, did not ablate recognition of the $60 \mathrm{kDa}$ band by autologous antibody, when compared to control. Of note, following trypsin digestion a new band, detected by autologous antibody, was present at $55 \mathrm{kDa}$. Exposure to neuraminidase did not ablate recognition of the antigen by autologous antibody.

\section{Antigen purification}

Preparative purification of the antigen was accomplished by anion exchange followed by lectin affinity chromatography on a Triticum vulgaris column. As illustrated in Fig. 6, spent media and antigen-containing fractions obtained following sequential anion exchange and lectin affinity chromatography were subjected to SDS-PAGE and silver stain. Following lectin affinity chromatography, a single protein band is noted at $60 \mathrm{kDa}$. No other bands previously noted in unfractionated spent media or following anion-exchange chromatography are seen. It is possible that other contaminants are still present but are below the level of detection with silver stain. Overloading of the gel may demonstrate this; however, the homogeneity of this material will only be determined if protein sequencing reveals a single peptide. Further confirmation that the antigen of interest had been purified is illustrated in Fig. 7, where a Western blot of the same antigenic material, run concurrently, again demonstrates a similar, single $60 \mathrm{kDa}$ band detected by autologous antibody. This band also corresponds to a similar band noted in serum ultrafiltrate obtained following acid dissociation and ultrafiltration.

Measurement of antigen activity and protein concentration following each purification step is shown in Table III. Antigen activity only increased from $1300 \times$ to $1600 \times$ following lectin affinity chromatography. As seen in Table III, the antigen was detected in a broad peak across a number of fractions which may have lead to dilution and loss of antigen following elution from the lectin column. Determination of the protein concentration following lectin affinity chromatography failed to reveal any detectable protein as measured by both the Bradford dye-binding procedure and microBCA assay. Based on the detection of a single faint band by silver stain, we estimate that the final concentration of antigen was approximately $1 \mu \mathrm{g} / \mathrm{ml}$ [25].

\section{Discussion}

The primary impetus for these studies has been the observation that patients with SCCHN and other malignant tumors produce an antibody directed against their own tumor $[9,11,18]$. Evaluation of the autologous immune response has been impeded by the low incidence and titer of antibody in native sera. Our ability to consistently augment autologous antibody titers by acidification and ultrafiltration of serum has allowed these studies to proceed and lends support to the hypothesis that circulating immune complexes are a reservoir for tumor-associated antigens and antibody relevant to the host. Of the $8 \mathrm{SCCHN}$ and 21 melanoma systems studied, augmented autologous antibody directed against the patient's own tumor has been found following $\mathrm{AD} \& \mathrm{U}$ in all but one case. It would appear that autologous antibody directed against SCCHN and melanoma is the rule rather than the exception.

Melanoma and SCCHN are distinct diseases with 

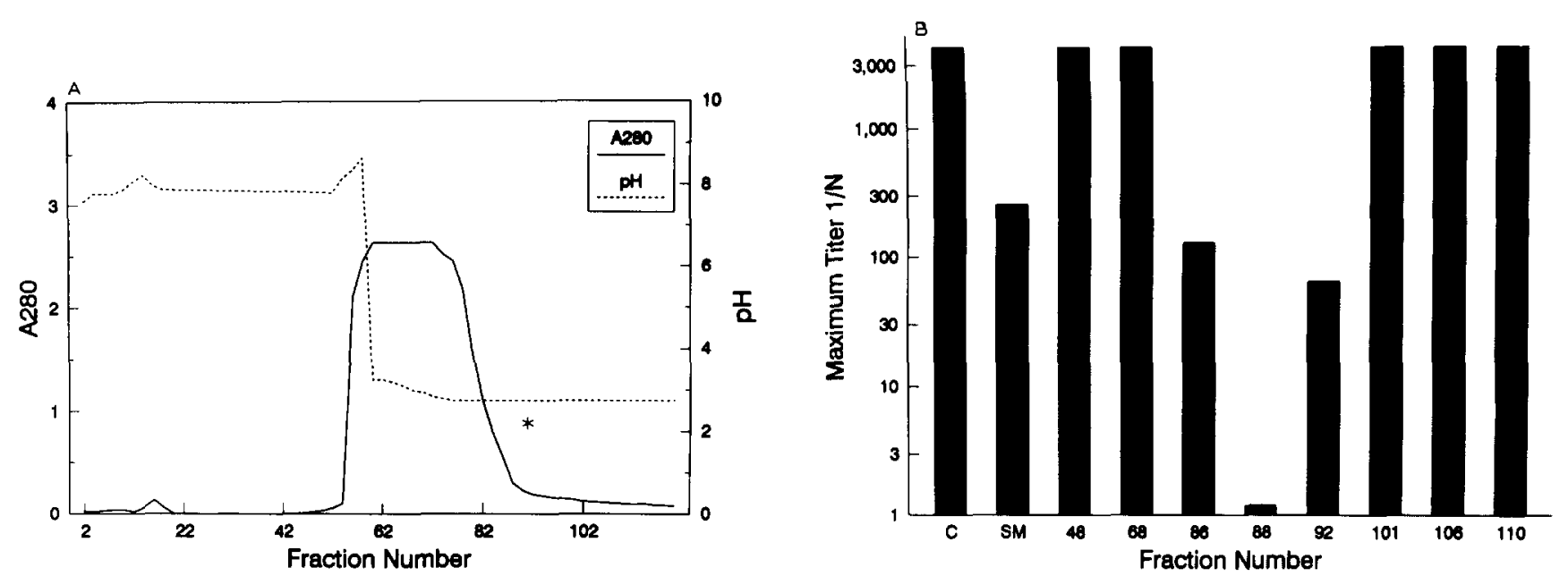

Fig. 3. Anion-exchange chromatography of spent media. $3 \mathrm{ml}$ of concentrated spent media (final protein concentration $300 \mathrm{mg} / \mathrm{ml}$ ) was applied to a $1.8 \times 15.5 \mathrm{~cm}$ Whatman DE-52 weak anion-exchange column that had been equilibrated with $0.02 \mathrm{M}$ Tris formate (pH 8.0 ). The $\mathrm{pH}$ was changed in stepwise fashion with $0.5 \mathrm{M}$ sodium formate $(\mathrm{pH} 2.8)$. Fractions were collected, dialyzed against PBS and tested for the presence of antigen by competitive inhibition. (b) Competitive inhibition of autologous antibody reactivity following anion-exchange chromatography. Autologous antibody reactivity was reduced by samples obtained from factions $86-91$ (Fig. 4b). This corresponds to the second small shoulder on the major peak noted on the chromatograph (see "*”, Fig. 4a). No other fractions were noted to contain the antigen. The location of the antigen-containing fractions which eluted after bulk serum albumin suggests that this antigen is acidic with a $\mathrm{p} I<4$. Control serum (C) is noted to have a maximum titer of $1: 2048$. The addition of unfractionated spent media (SM) reduced autologous antibody titers to 1:256.

different natural histories, clinical courses etc. It may be argued that melanoma and SCCHN represent two opposite ends of the spectrum in regard to cancer immunobiology. Melanoma is perhaps the most immunogenic cancer studied with well documented instances of spontaneous regression. SCCHN, on the other hand, has a natural history that is more frequently associated with immunosuppression [26]. Because SCCHN represents the 'other end of the spectrum' we extended our serologic studies in that direction. Determination of the similarities and differences that exist in the host immune response to these two very different cancers may lead to a better overall understanding of the host-tumor interaction. Our re- sults indicate that, as with melanoma, autologous antibody reactivity to SCCHN can be enhanced by dissociation of immune complexes and that fluctuations in autologous antibody titers show correlations with clinical course $[9,14]$. The fact that similar observations can be made in two such disparate tumors invites further investigation and comparison.

Because the source of antibody is serum, evaluation of the distribution of the antigen has been limited. Immunohistologic analysis is precluded by the large amount of sera required and the difficulty in characterizing specificity using human sera on human tissues. As a consequence, we and others have performed specificity analysis to evaluate antibody reactivity

\section{TABLE II}

Lectin binding to SCCHN antigen

0 , absent; + , faint; ++ , present; +++ , strong.

\begin{tabular}{|c|c|c|}
\hline Lectin & Binding & Known binding oligosaccharide \\
\hline Riticum vulgaris & ++ & $\operatorname{GlcNAc}(\beta(1,4) \mathrm{GlcNAc})_{2}>\beta$-GlcNAc, $\alpha$-NeuAc (sialic acid) \\
\hline Canavalia ensiformis & ++ & $\alpha$-man $>\alpha$-Glc \\
\hline Dolichos biflorus & ++ & GalNAc(1,3)GalNAc \\
\hline Arachis hypogaea & 0 & Gal $\beta(1,3)$ GalNAc $>$ Gal \\
\hline Lycopersicon esculentum & + & $\operatorname{GlcNAc}(\beta(1,4) \text { GlcNAc })_{1-3}$ \\
\hline Phytolacca americana & 0 & $\operatorname{GlcNAc}(\beta(1,4) \mathrm{GlcNAc})_{1-5}=\left(\operatorname{Gal}(\beta(1,4) \mathrm{GlcNAc})_{2-5}\right.$ \\
\hline Glycine max & 0 & $\alpha$ - and $\beta$-GalNAc \\
\hline Erythina cristagalli & ++ & {$[D-G a l-(1,4)-G I c N A c]>-G a l N A c$} \\
\hline Vicia villosa & ++ & $\alpha$-GalNAc \\
\hline Griffonia simplicifolia II & $+t+$ & $\alpha$-GlcNAc, $\beta$-GlcNAc \\
\hline Griffonia simplicifolia I-B4 & 0 & $\alpha$-D-Gal \\
\hline Maackia amurensis & ++ & NANA $\alpha(2,3)$ Gal $\beta(1,4)$ Glc \\
\hline Ricin communis & + & D-Gal- $\beta(1,3)$ GalNAc \\
\hline
\end{tabular}


against a range of neoplastic and non-neoplastic cell lines. Specificity analysis of UM-SCC-17 and six other autologous systems has been previously reported $[9,14]$ and have demonstrated a similar degree of reactivity. All appear to be detecting a class Il antigen that is present on SCCHN and melanoma cell lines but not on normal cell constituents. While utilization of additional cell lines would be of interest it will not aid in the determination of the antigen's composition. Our success in purifying the antigen to apparent homogeneity will now permit evaluation of its composition.

We concentrated our efforts on the isolation and characterization of the antigen present in spent tissue culture media as it provides an unlimited and repetitively accessible source of antigen for study. While it may be argued that the antigen present in spent tissue culture media may be different than that bound to the antibody in serum, the evidence we have to date would argue that they are the same. Competitive inhibition with antigen obtained from serum, spent media or whole cells reduced binding of antibody to autologous SCCHN cells. Finally, a Western blot of spent media and serum ultrafiltrate revealed the same $60 \mathrm{kDa}$ antigen (Fig. 7).

As illustrated in Fig. 6, we have succeeded in purifying, to apparent homogeneity, a SCCHN-associated antigen, identified by autologous antibody, by anion-exchange followed by lectin affinity chromatography with a Triticum vulgaris column. Following lectin affinity chromatography, a single protein band, previously detected by Western blot of unfractionated spent media, was noted at $60 \mathrm{kDa}$. No other bands previously seen in unfractionated spent media or following anion-exchange chromatography were seen. A Western blot of

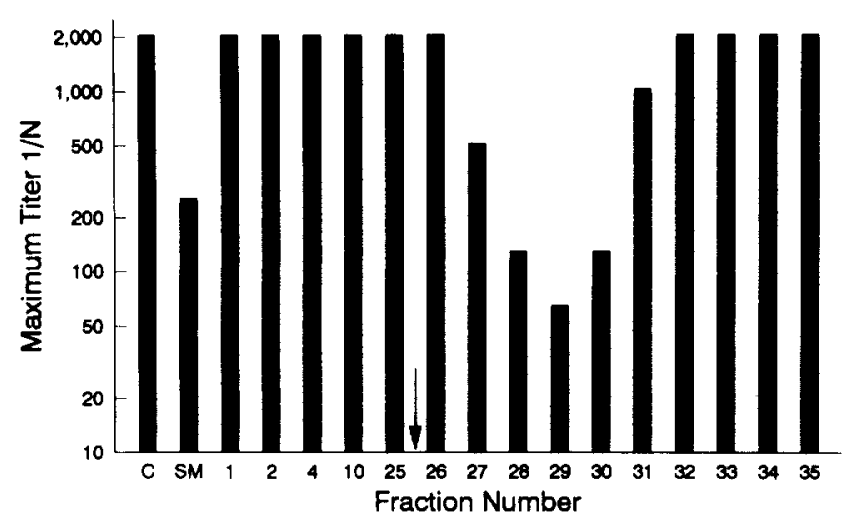

Fig. 4. Lectin affinity chromatography $4 \mathrm{ml}$ of antigen obtained following anion exchange chromatography was applied to a $10 \mathrm{ml}$ sepharose column bound with Triticum vulgaris (E-Y Laboratories, San Mateo, CA) and allowed to equilibrate for $30 \mathrm{~min}$. Antigen binding to the column was eluted (see arrow) with $0.5 \mathrm{M}$ GlcNAc, dialyzed and tested for the presence of antigen by competitive inhibition. Antigen was detected in elution fractions 27-31. Control serum $(C)$ is noted to have a maximum titer of $1: 2048$. The addition of unfractionated spent media (SM) reduced autologous antibody titers to 1:256.
UM-SCC-17A
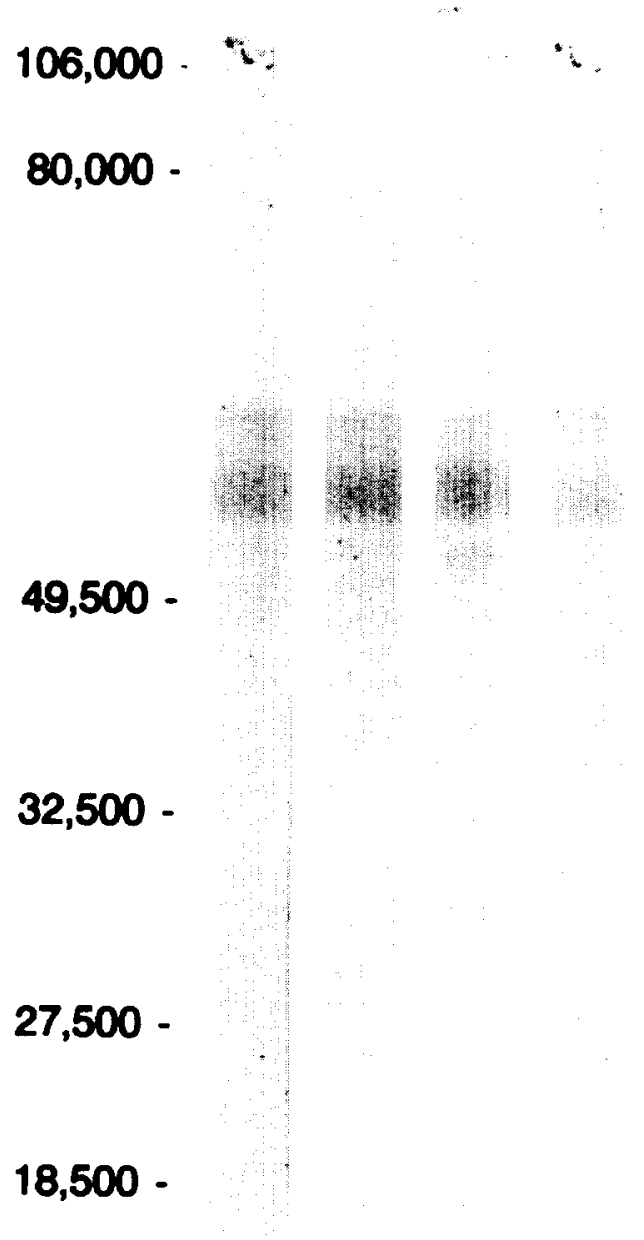

\begin{abstract}
$\begin{array}{llll}C & \boldsymbol{P} & \mathbf{T} & \mathbf{N}\end{array}$
Fig. 5. Enzymatic digestion of SCCHN antigen. Preincubation of partially purified SCCHN antigen obtained following anion-exchange chromatography with pepsin (lane P) or trypsin (lane $T$ ) did not ablate recognition of the antigen, detected by autologous antibody, when compared to control (lane C). Following exposure to trypsin a new band $(\sim 55 \mathrm{kDa})$ is noted. Exposure of the antigen to neuraminidase prior to SDS-PAGE (lane N) did not alter recognition of the antigen by autologous antibody when compared to control (lane C). The excessive width of the bands are due to intentional overloading of the gel to better aid in detecting differences
\end{abstract}

the purified antigen again revealed a single $60 \mathrm{kDa}$ band of similar size and shape (Fig. 7). It is possible that other contaminants are still present but are below the level of detection with silver stain. Overloading of the gel may demonstrate this; however, the absolute homogeneity of this material will be confirmed if protein sequencing reveals a single peptide. Measurement of protein concentration following each purification step is shown Table III. Determination of the protein concentration following lectin affinity chromatography 
is difficult as the level was below the limits of detection of the two assays used. Based on the detection of a single faint band by silver stain, we estimate that the final yield of antigen was approximately $12 \mu \mathrm{g}$ [25]. The low concentration of detectable protein adds additional weight to our belief that other contaminating proteins have been removed. While the final protein concentration was small $(1 \mu \mathrm{g} / \mathrm{ml})$, the relative antigenic activity increased $1600 \times$ when compared to unfractionated spent media. This represents the first successful isolation and purification, to apparent homogeneity, of a SCCHN-associated antigen recognized by the host.

Initial characterization of the isolated SCCHN-associated antigen indicates that it is an acidic glycoprotein based on anion-exchange and lectin affinity chromatography. As illustrated in Table II, lectin binding was noted to 9 of 13 biotinylated lectins. The strongest binding was noted with Triticum vulgaris and Griffonia simplicofolia II. Binding to these two lectins is consistent with the presence of a $\beta$ - $(1 \rightarrow 4)$-linked oligomer

\section{UM-SCC 17A}

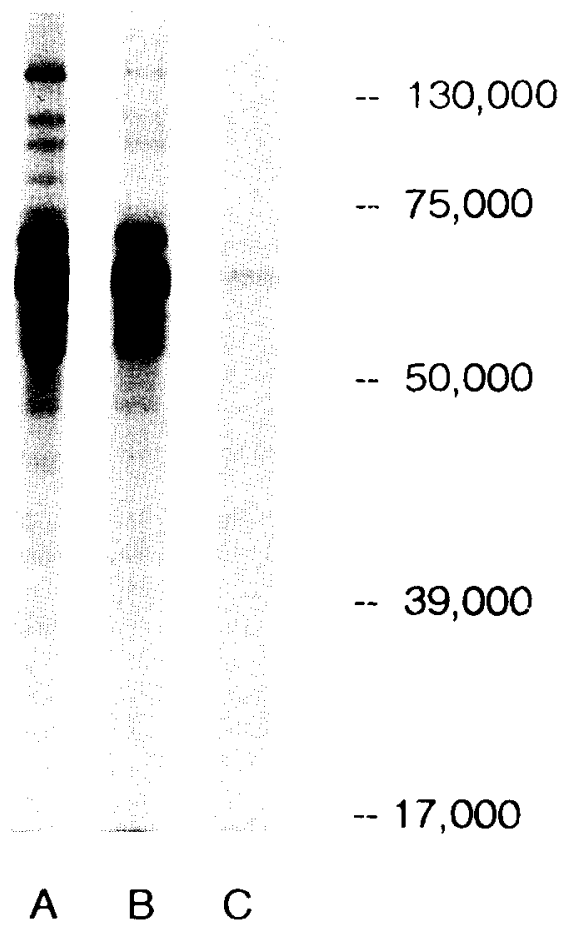

Fig. 6. SDS-PAGE analysis of each step of purification of a SCCHN-associated antigen. Silver stain of a gel of unfractionated spent tissue culture media (lane A), and following isolation by anion-exchange (lane B) and lectin affinity (lane C) chromatography. Following lectin affinity chromatography a single protein band is noted at $60 \mathrm{kDa}$. No other bands previously noted in unfractionated spent media or following anion-exchange chromatography are seen. Due to the large quantity of protein in unfractionated spent media it was diluted $1: 20$ before being run on the gel.

\section{UM-SCC-17A}

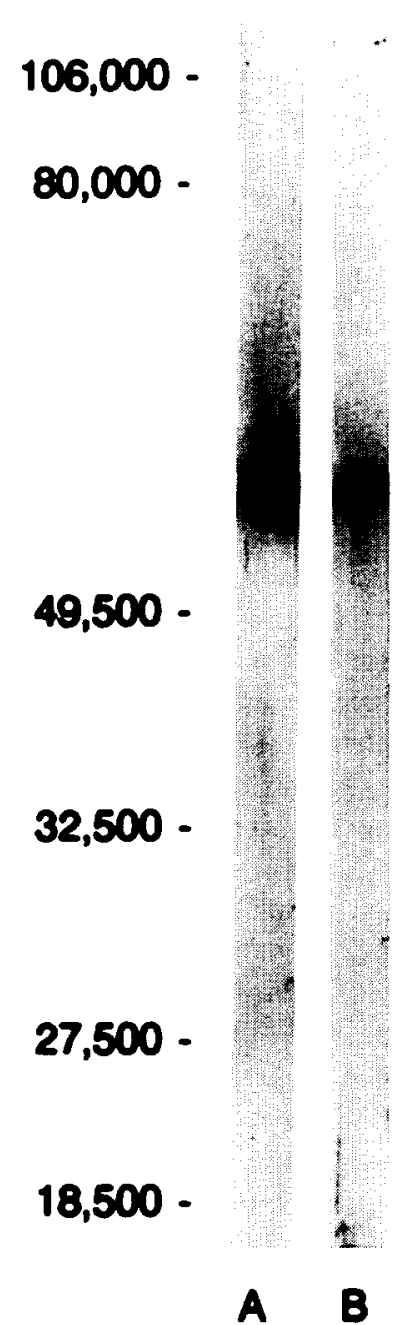

Fig. 7. Western blot analysis of SCCHN antigen. Antigen obtained from serum ultrafiltrate (lane A) or following lectin affinity chromatography (lane B) was subjected to Western blot analysis and immunoblot with autologous antibody. A single band at $60 \mathrm{kDa}$ is noted in both lanes corresponding to the protein band seen following silver stain (see Fig. 7).

of $\mathrm{N}$-acetyl-D-glucosamine on the antigen [27] an observation which is confirmed by our ability to subsequently increase the specific antigenic activity by

TABLE III

Purification of a $60 \mathrm{kDa} S C C H N$-associated antigen

\begin{tabular}{lccc}
\hline Purification step & $\begin{array}{l}\text { Volume } \\
(\mathrm{ml})\end{array}$ & $\begin{array}{l}\text { Protein } \\
(\mathrm{mg} / \mathrm{ml})\end{array}$ & $\begin{array}{l}\text { Relative } \\
\text { activity }^{\text {a }}\end{array}$ \\
\hline Spent media & 3 & 300 & 1 \\
Anion exchange & 20 & 0.16 & 1300 \\
Lectin & 12 & $0.001^{\mathrm{b}}$ & 1600 \\
\hline
\end{tabular}

a Based upon dilution of antigen required to give same reduction in autologous antibody titer against SCCHN cell line UM-SCC-17A as unfractionated spent media.

b Estimate based upon single band on silver stain. 
Triticum vulgaris affinity purification. Enzymatic digestion of partially purified antigenic material with trypsin or pepsin did not ablate recognition of the antigen by autologous antibody. Of additional note, exposure of the antigen to neuraminidase did not affect dectection by autologous antibody. This would suggest that sialic acid is not part of the antigenic epitope. However, given its acidic nature $(\mathrm{p} /<4)$ it is quite likely that sialic acid is a component of the antigen.

The cross reactivity of the autologous SCCHN antibody with melanoma-derived antigenic material indicates that similar antigens are present on both tumor types. Until the protein and carbohydrate composition of the melanoma and SCCHN antigens are determined the similarities and differences between these antigens will not be known. While cross-reactivity of the SCCHN and melanoma-associated antigen has been documented, significant differences have been noted as well. The distribution of the melanoma-associated antigen, defined by sera from melanoma patients, was much broader with cross reactivity noted against melanoma, glioma, renal cell carcinoma, neuroblastoma, and head and neck carcinoma cell lines [13]. In addition, many more lectins were noted to bind to the SCCHN antigen suggesting a distinct carbohydrate composition. Furthermore, in contrast to melanoma, recognition of the SCCHN-associated antigen by autologous antibody was not ablated by exposure to neuraminidase or trypsin. A $16 \mathrm{~h}$ exposure of the SCCHN antigen to trypsin did not ablate the $60 \mathrm{kDa}$ band. Conversely, exposure of the melanoma-associated antigen to trypsin for only $30 \mathrm{~min}$ ablated recognition of the $66 \mathrm{kDa}$ antigen by autologous antibody and led to the development of a new $24 \mathrm{kDa}$ band [13].

Other investigators are beginning to explore the nature of tumor-associated antigens that elicit T-cellmediated immunity in patients with cancer. Van der Bruggen et al. [28] recently reported the successful cloning of a gene encoding an antigen recognized by cytotoxic $\mathrm{T}$ lymphocytes in patients with melanoma. Those findings complement our results whose significance lies in the ability of the antigen to elicit a humoral response in patients with SCCHN. The ultimate goal of all these studies is to delineate the significance and biologic role of tumor-associated antigens that are immunogenic to the host. As a better understanding emerges, it may be possible to develop tumor vaccines for the treatment or prevention of cancer.

\section{Acknowledgements}

The authors would like to thank Dr. Barry Solomon, vice president for research at W.R. Grace \& Co., for technical advice. The work was supported, in part. by National Institutes of Health Grant RO1 CA49708.

\section{References}

1 Mitchell, K.F., Fuhrer, J.P., Steplewski, Z. and Koprowski, H. (1980) Proc. Natl. Acad. Sci. USA 77, 7287-7291.

2 Taj, T., Paulson, J.C., Cahan, L.D. and Iric. R.F. (1983) Proc. Natl. Acad. Sci. USA 80, 5382-5396.

3 Scheinberg, D.A. and Houghton, A.N. (1987) Oncology 1, 31-40.

4 Kimmel, K.A. and Carey, T.E. (1983) Cancer Res. 46. 3614-3623.

5 Eskinazi, D.P., Molinaro, G.A., Abermayor, E., Martin, S.E. and Zighelboim, J. (1985) Oral Surg. Oral Med. Oral Pathol. 60. $377-381$.

6 Fantozzi, R.D. (1991) Laryngoscope 10, 1076-1080.

7 Quak, J.J., Gerretsen, M., Schrivers, A.H., Van Dongen, G.A. and Snow, G.B (1991) Arch. Otolaryngol. Head Neck Surg. 117. 1287-1291.

8 Schrijvers, A.H., Gerretsen, M., Fritz, J.M., Quak, J.J., Snow, G.B. and Van Dongen, G.A. (1991) Exp. Cell. Res. 196, 264-269.

9 Vlock, D.R., Scalise, D., Schwartz, D.R., Richter, D.E., Krause, C.J.. Baker, S.R. and Carey, T.E. (1989) Cancer Res. 49, 13611365.

10 Carey, T.E., Kimmel, K.A., Schwartz, D.R., Richter, D.E., Baker. S.R. and Krause, C.J. (1983) Otolaryngol. Head Neck Surg. 91. $482-491$.

11 Kirkwood, J.M. and Vlock, D.R. (1984) Cancer Res. 44, 4177 4182.

12 Vlock, D.R. and Kirkwood, J.M. (1985) J. Clin. Invest. 76, 849. 854.

13 Vlock, D.R., Scalise, D., Meglin, N., Kirkwood, J.M. and Ballou, B. (1988) J. Clin. Invest. 81, 1746-1751.

14 Vlock, D.R., Arnold, B., Humpierres, J., Schwartz, D.R., Baker. S.R., Krause. C.J., Swanson, N. and Carey, T.E. (1992) Cancer Immunol. Immunother. 34, 329-336.

15 Vlock, D.R. (1990) Immunol. Ser. 53, 555-586.

16 Vlock, D.R., Aul, D.J., Toporowicz, A., McCoy, J.P. and Brown, W.E. (1991) Biochim. Biophys. Acta 1080, 1-10.

17 Carey, T.E., VanDyke, D.L., Worsham, M.J., Bradford, C.R., Babu, V.R., Schwartz, D.R., Hsu, S. and Baker, S.R. (1989) Cancer Res. 49, 6098-6107.

18 Pfreundschuh, M., Shiku, H., Takahashi, T., Ueda, R., Ransohoff, J., Oettgen, H.F. and Old, L.J. (1978) Proc. Natl. Acad. Sci. USA $75,5122-5126$.

19 Sjogren, H.O., Hellstrom, I., Bansal, S.C. and Hellstrom. K.E. (1971) Proc. Natl. Acad. Sci. USA 68, 1372-1375.

20 Laemmli, U.K. (1970) Nature 227, 680-685.

21 Towbin, H., Staehelin, T. and Gordon. J. (1979) Proc. Natl. Acad. Sci. USA $76,4350-4354$.

22 Bradford, M.M. (1976) Anal. Biochem. 72, 248-254.

23 Merril, C.R. (1990) Methods Enzymol. 182, 477-488.

24 Wray, W., Boulikas, T., Wray, V.P. and Hancock, R. (1981) Anal. Biochem. 118, 197-203.

25 Furukawa, K., Yamaguchi, H., Oettgen, H.F., Old. L.J. and Lloyd, K.O. (1989) Cancer Res. 49, 191-196.

26 Vlock, D.R. (1991) Hematol/Oncol. Clin. N. Am. 5, 797-819.

27 Liener, I.E., Sharon, N. and Goldstein, I.J. (1986) The lectins: properties, function and application in biology and medicine, Academic Press, New York.

28 Van der Bruggen, P., Traversari, C., Chomez, P., Lurquin, C., De Plaen, E., Van den Eynde, B., Knuth, A. and Boon, T. (1991) Science 254, 1643-1647. 